\title{
Strabismus in Cases of Cataract in Pediatric Age Group*
}

\author{
Shreya M. Shah, Mehul A. Shah, Pramod R. Upadhyay, Geetopam B. Bardoloi, Drashti Netralaya" \\ Drashti Netralaya, Dahod, India. \\ Email: \#omtrust@rdiffmail.com
}

Received October 21 $1^{\text {st }}, 2012$; revised November $21^{\text {st }}, 2012$; accepted November $28^{\text {th }}, 2012$

\begin{abstract}
Purpose: To investigate the epidemiology of strabismus in cases of pediatric cataracts. To assess visual outcome following orthoptic treatment for amblyopia in cases of cataracts in the pediatric age group. Methods: This was a retrospective cohort study. We investigated a consecutive series of pediatric patients with congenital, developing, or traumatic cataracts who underwent surgery between January 1999 and April 2012 at our center. Patient demographics, cataract type, presenting symptoms, surgical intervention, postoperative visual acuity, and follow-up refractive changes were recorded. Results: In total, 1331 eyes of 1043 children were included: unilateral cataracts were present in 785 $(59 \%)$ eyes. There were $605(45.5 \%)$ traumatic and $726(54.5 \%)$ non-traumatic cases. Ages at surgery ranged from 1 to 215 months. All eyes were examined for ocular alignment; 66 (5\%) were found to manifest strabismus. Deviation was significantly associated with age at intervention $(p<0.001)$, sensory nystagmus $(p<0.001)$, and etiology of cataracts $(p$ $<0.001)$. We found significant differences in visual outcome following amblyopia therapy $(p<0.001)$. Conclusions: Surgical treatment with intraocular lens implantation in children with congenital, developmental, or traumatic cataracts is effective for visual rehabilitation. Orthoptic treatment made a significant difference in visual outcome $(p<0.001)$.
\end{abstract}

Keywords: Pediatric Cataract; Visual Outcome; Traumatic Cataract; Developmental Cataract; Congenital Cataract

\section{Introduction}

Childhood cataracts are responsible for $5 \%-20 \%$ of blindness in children worldwide and for an even higher percentage of childhood visual impairment in developing countries [1-5]. The overall incidence of clinically significant cataracts (unilateral or bilateral) in childhood is unknown, but has been estimated to be as high as $0.4 \%$. $[6,7]$. The prevalence of childhood cataracts varies from 1.2 to 6.0 cases per 10,000 infants. Pediatric cataracts are responsible for more than 1 million cases of childhood blindness in Asia. In developing countries, such as India, $7.4 \%-15.3 \%$ of childhood blindness is due to cataracts. $[8,9]$ Internationally, the incidence is unknown. Although the World Health Organization and other health organizations have made great progress in vaccination and disease prevention, the rate of congenital cataracts remains much higher in underdeveloped countries.

The visual results of cataract surgery in children have generally $[10,11]$ been poorer than in adults $[1-3,6,11,12]$. This difference is due, in part, to the various types of amblyopia that develop in children with cataracts, the association of nystagmus with early onset cataracts, and the

\footnotetext{
*No financial support received from any company or institution, This study is not presented at any conference or meeting, Authors do not have any financial interest in any aspect of this study

\#Corresponding author.
}

presence of other ocular abnormalities that adversely affect vision in eyes with developmental lens opacities. Since the introduction of the aspiration technique of cataract removal by Scheie in 1960 [13], surgical procedures for the removal of the lens in childhood have improved $[14,15]$, and earlier surgery for congenital cataracts has been encouraged [16-18]. Strabismus and amblyopia are important causes of poor visual outcome. [18].

Any opacification of the lens and its capsule in children is defined as a pediatric cataract. Pediatric cataracts can be unilateral or bilateral. They can be subdivided based on morphology, as well as etiology. Morphologically, the most common type of pediatric cataract is the zonular cataract, characterized by opacification of a discrete region of the lens. This type includes nuclear, lamellar, sutural, and capsular cataracts $[6,10]$.

Congenital cataracts are one of the most common causes of treatable blindness in children, particularly in developing countries [1]. A recent report indicated that infants with bilateral congenital cataract who underwent early surgery (within 1 month of birth) and received appropriate optical rehabilitation could obtain visual acuity of better than 0.4 and could even achieve stereopsis [2]. However, because of typically relatively late detection and diagnosis, the lack of availability of facilities for 
ininfant anesthesia, and poor compliance with long-term follow-up, the visual prognosis for infants with congenital cataract in developing countries differs markedly from that in industrialized nations. Visual loss is primarily attributable to amblyopia, most importantly, to "stimulus-form deprivation amblyopia" with the additional factor of ocular rivalry in unilateral disease. Thus, improved understanding of the critical periods of visual development has resulted in surgical intervention for dense cataracts being deemed necessary within the first 3 months of life, possibly as early as the first 6 weeks in unilateral disease. Clinical factors believed to be important to visual outcome in children include age at diagnosis and surgery, type of refractive correction, type of cataract surgery, compliance with an occlusion regimen, etiology of the cataract, presence of non-ophthalmic disorders, development of capsular opacity or secondary membrane, and serious ocular postoperative complications.

\section{Materials and Methods}

The study was approved by the hospital ethics committee. This was a prospective hospital-based study at a tertiary care eye hospital in western India over 20 years, from January 1992 to April 2012. All pediatric patients $(0-18)$ with cataracts presenting to our department during this period were enrolled in the study. Primary patient details and history were documented using a pre-tested online format. Ocular trauma details were documented with an online world eye injury registry form.

Gifting Vision was checked according to the American Academy of Pediatrics vision check protocol. Both eyes were assessed [19]. Anterior segment examinations were conducted using a slit lamp bio-microscope. The pupils were dilated.

Ocular pressure was measured using a Perkin's handheld tonometer. If this was not possible, the pressure was measured under general anesthesia. This procedure was omitted for eyes with open globe injuries. The posterior segment of the eye was evaluated with the help of an indirect ophthalmoscope, a +20 D lens, and an ultrasound 'B' scan if the media was not clear. The surgical technique was decided based on etiology, cataract morphology, and the position of the lens. Surgery was conducted by the anterior or pars plana route. Anterior route surgeries were performed using a phacoemulcifier or manual suction. Membranectomies and lensectomies were performed using a pneumatic cuter. Intraocular lenses were not implanted in patients younger than 1.5 years. Children below this age underwent lensectomies/membranectomies; secondary implant placement was conducted later. Patients were rehabilitated using glasses or contact lenses in-between. For IOL power calculations, we followed published guidelines [20,21].
In cases of globe rupture, open globe injury wound repair was done as a first stage and the cataract was operated on at a second sitting. All steps of the surgical techniques were documented using a pretested online format.

All traumatic cataract patients without infection were treated with systemic corticosteroids. In all patients with inflammation and membranous cataracts, a primary posterior capsulotomy and anterior vitrectomy were performed.

Postoperative follow-up was performed according to a pretested online format, including vision, anterior and posterior segment findings, and intraocular pressure, over an appropriate follow-up schedule. Glasses were prescribed when the media were clear and the final prescription was at 6 weeks post-operation. Patients underwent orthoptic evaluations and amblyopic patients were treated with appropriate patching. Aphakic patients were rehabilitated using glasses or contact lenses. Patients were evaluated for stereopsis and contrast sensitivity using a Titmus vision tester or a Titmus fly test.

Patients developing later cataracts underwent membraneectomies and vitrectomies as required. For children operated on below the age of 1.5 years, secondary lens implantation was performed after they reached 2 years of age.

Data were analysed using the SPSS software (ver. 19.0; SPSS Inc., Chicago, IL, USA). Univariate parametrical analyses were used. A $P$ value of $<0.05$ was considered to indicate statistical significance.

\section{Results}

The enrolled patient group consisted of 1331 eyes in 1043 pediatric patients with cataracts. There were 867 (65.1\%) males and 464 (34.9\%) females (Table 1). The mean patient age was $4.1 \pm 1.06$ (range, 0 - 18) years. Of the cataracts, $605(45.5 \%)$ were traumatic and $726(54.4 \%)$ were congenital or developmental. Of the eyes, 1145 (86\%) had diminished vision and 188 (14.0\%) presented with leucokoria. The follow-up period was 1 - 3084 (mean, 117.4) days.

Table 1. Age and gender distributions.

\begin{tabular}{cccc}
\hline \multirow{2}{*}{ AGE AT INTERVENTION } & \multicolumn{2}{c}{ GENDER } & Total \\
\cline { 2 - 3 } & FEMALE & MALE & \\
\hline $1-3$ & 20 & 31 & 51 \\
$4-5$ & 37 & 46 & 83 \\
$6-10$ & 46 & 91 & 137 \\
$11-18$ & 165 & 305 & 470 \\
Total & 196 & 394 & 590 \\
& 464 & 867 & 1331 \\
\hline
\end{tabular}


We found strabismus in 66 (5\%) cases (Tables 2 and 3). We compared strabismus according to age of intervention. A significant association with strabismus was found in the younger age group (Table 2; $P<0.001$ ).

In the non-traumatic group, eyes were further subdivided into congenital (282, 21.2\%), developmental (415, $31.2 \%)$, and secondary cataracts $(29,2.2 \%)$. According to the statistical analysis, the demographic factors analyzed, including socioeconomic status $(74.5 \%$ were of lower socioeconomic status) and residence (92\% were from rural areas), had no significant relationship with final visual acuity. When compared with category, strabismus was less commonly associated with traumatic cataracts (Table 4; $P<0.001$ ).

Regarding patient entry, $9.2 \%$ of the patients had received primary treatment prior to reaching our center; this was not associated with a significant difference in the final visual outcome $(P=0.2)$. Of the total patients enrolled, $26.4 \%$ entered via an outreach department, and $71 \%$ were self-referred.

Table 2. Strabismus according to age.

\begin{tabular}{|c|c|c|c|}
\hline \multirow{2}{*}{ AGE AT INTERVENTION } & \multicolumn{2}{|c|}{ SQUINT } & \multirow{2}{*}{ Total } \\
\hline & NO & YES & \\
\hline$\leq 1$ & 44 & 7 & 51 \\
\hline $1-3$ & 70 & 13 & 83 \\
\hline $4-5$ & 131 & 6 & 137 \\
\hline $6-10$ & 455 & 15 & 470 \\
\hline $11-18$ & 565 & 25 & 590 \\
\hline Total & 1265 & 66 & 1331 \\
\hline
\end{tabular}

$P<0.001$.

Table 3. Amblyopia according to age.

\begin{tabular}{cccc}
\hline \multirow{2}{*}{ AGE OF INTERVENTION } & \multicolumn{2}{c}{ AMBLYOPIA } & \multirow{2}{*}{ Total } \\
\cline { 2 - 3 } & -1.00 & 0.00 & \\
\hline$\leq 1$ & 9 & 42 & 51 \\
$1-3$ & 17 & 66 & 83 \\
$4-5$ & 11 & 126 & 137 \\
$6-10$ & 19 & 451 & 470 \\
$11-18$ & 18 & 572 & 590 \\
Total & 74 & 1257 & 1331 \\
\hline
\end{tabular}

$P<0.001$.

Table 4. Squint according to cataract etiology.

\begin{tabular}{cccc}
\hline \multirow{2}{*}{ CATEGORY } & \multicolumn{2}{c}{ SQUINT } & \multirow{2}{*}{ Total } \\
\cline { 2 - 3 } & NO & YES & \\
\hline TRAUMATIC & 595 & 10 & 605 \\
NON TRAUMATIC & 670 & 56 & 726 \\
Total & 1265 & 66 & 1331 \\
\hline
\end{tabular}

$P<0.001$.
Among the injuries, $30 \%$ were reported within the first $24 \mathrm{~h}, 30 \%$ were reported within 3 days, and $33.9 \%$ were reported within 1 month. A wooden stick was the most common object causing eye injury $(51.4 \%)$. Neither the injury-causing object $(P=0.3)$ nor the activity at the time of injury $(P=0.3)$ was significantly associated with the final visual acuity.

A comparison of pre- and post-operative visual acuities showed that treatment significantly improved visual acuity (Table 5; $P<0.001$, Pearson's $\chi^{2}$ test; $P=0.001$, ANOVA).

We examined unilateral versus bilateral cataracts (Table 6; $P<0.001$ ) and found a significant association with strabismus in bilateral cases.

Sensory nystagmus was present in $250(18.8 \%)$ eyes and was significantly associated with strabismus (Table 7; $P<0.001)$.

An intraocular lens was implanted in 1210 cases $(91.1 \%)$ and was not significantly associated with strabismus (Table 8; $P=0.137$ ).

When we studied the strabismus, we found that 35 (50.8\%) had esotropia, 29 (42\%) had exotropia, and five $(7.2 \%)$ had vertical strabismus with esotropia or exotropia (Table 9). In total, $36 \%$ cases had "special" forms

Table 5. Visual outcome pre-post-patching.

\begin{tabular}{cccccc}
\hline \multirow{2}{*}{$\begin{array}{c}\text { PRE PATCH } \\
\text { VISION }\end{array}$} & \multicolumn{5}{c}{ POST PATCH VISION } \\
\cline { 2 - 5 } & $<1 / 60$ & $1 / 60$ TO & $6 / 60$ TO & $6 / 24$ TO & Total \\
\hline$<1 / 60$ & 7 & 0 & 0 & 1 & 8 \\
$1 / 60$ TO $3 / 60$ & 2 & 21 & 0 & 0 & 23 \\
$6 / 60$ TO 6/36 & 0 & 4 & 4 & 0 & 8 \\
$6 / 24$ TO 6/18 & 1 & 0 & 2 & 27 & 30 \\
6/12 TO 6/9 & 0 & 0 & 3 & 1 & 4 \\
Total & 10 & 25 & 9 & 29 & 73 \\
\hline
\end{tabular}

Table 6. Strabismus compared with laterality.

\begin{tabular}{cccc}
\hline \multirow{2}{*}{ LATERALITY } & \multicolumn{2}{c}{ SQUINT } & \multirow{2}{*}{ Total } \\
\cline { 2 - 3 } & NO & YES & \\
\hline UNILATERAL & 763 & 22 & 785 \\
BILATERAL & 502 & 44 & 546 \\
Total & 1265 & 66 & 1331 \\
\hline
\end{tabular}

$P<0.001$.

Table 7. Strabismus compared with sensory nystagmus.

\begin{tabular}{cccc}
\hline \multirow{2}{*}{$\begin{array}{c}\text { SENSORY } \\
\text { NYSTAGMUS }\end{array}$} & \multicolumn{2}{c}{ SQUINT } & \multirow{2}{*}{ Total } \\
\cline { 2 - 3 } & NO & YES & \\
\hline YES & 1051 & 30 & 1081 \\
NO & 214 & 36 & 250 \\
Total & 1265 & 66 & 1331 \\
\hline
\end{tabular}

$P<0.001$. 
Table 8. Strabismus compared with the presence of IOL.

\begin{tabular}{cccc}
\hline \multirow{2}{*}{ IOL } & \multicolumn{2}{c}{ SQUINT } & \multirow{2}{*}{ Total } \\
\cline { 2 - 3 } & NO & YES & \\
\hline YES & 1153 & 57 & 1210 \\
NO & 112 & 9 & 121 \\
Total & 1265 & 66 & 1331 \\
\hline
\end{tabular}

$P=0.137$

Table 9. Type of strabismus.

\begin{tabular}{ccc}
\hline TYPE & NUMBER $(n)$ & PERCENT (\%) \\
\hline ESOTROPIA & 35 & 50.8 \\
VERTICAL & 5 & 7.2 \\
EXOTROPIA & 29 & 42.0 \\
Total & 69 & 100.0 \\
\hline
\end{tabular}

of strabismus, like A pattern, V pattern, or dissociated vertical deviation. In cases with strabismus, 37 (53.6\%) had sensory nystagmus and $56(81.2 \%)$ had amblyopia.

\section{Discussion}

The enrolled patient group consisted of 1331 eyes in 815 pediatric patients with cataracts. There were $867(65.1 \%)$ males and 464 (34.9\%) females (Table 2). The mean patient age was $4.1 \pm 1.06$ (range, 0 - 18) years. Of the cataracts, $605(45.5 \%)$ were traumatic and $726(54.4 \%)$ were congenital or developmental. The mean patient age was $4.1 \pm 1.6$ years. The mean age in another report was 7.1 [22]. Age at intervention had a significant effect on visual outcome (Table 2). Other investigators have reported similar findings [23].

The incidence of traumatic cataracts in children was higher than that reported previously [24]. In a compareson of the traumatic and non-traumatic groups, the group with traumatic cataracts had a significantly lower incidence of strabismus, likely attributable to the more fully developed visual system in children in traumatic cases. Spanou et al. reported strabismus in 23\% and Magli et al. reported a $34 \%$ incidence of strabismus in contrast to only $5 \%$ in our study $[25,26]$, perhaps because of the larger number of traumatic cataracts. Regarding unilateral and bilateral cases, we found a higher incidence of strabismus in bilateral cataracts in contrast to another report [25].

A retrospective study of the outcome of surgery for cataracts in the pediatric age group has several limitations. Although we believe that all patients included in the study had congenital, developmental, or traumatic lens opacities, not all patients were seen and followed by us from the time of birth. In particular, some patients with lamellar cataracts were not seen by us until they were several years old.
Treatment of strabismic amblyopia following bilateral congenital cataract surgery is useful, although the ocular misalignment is sometimes hard to identify, and the amblyopia may be profound by the time it is recognized [ 10 , 27]. Deprivational amblyopia due to asymmetry of cataracts from the outset is very difficult to reverse, similar to the situation in patients with monocular congenital cataracts. An early start of treatment would seem to be the only hope of success in these asymmetric cases [10].

In conclusion, the incidence of strabismus in cases of pediatric cataract was only $5 \%$, was more common in the non-traumatic group and bilateral cases in the younger age group. Orthoptic treatment had a significant effect on visual outcome.

\section{REFERENCES}

[1] V. Long and S. Chen, "Surgical Interventions for Bilateral Congenital Cataract," Cochrane Database of Systematic Reviews, Vol. 19, No. 3, 2006, Article ID: CD003171. doi:10.1002/14651858.CD003171.pub2

[2] M. A. Zimmermann-Paiz, and C. R. Quiroga-Reyes, "Pediatric Cataract in a Developing Country Retrospective Review of 328 Cases," Arquivos Brasileiros de Oftalmologia, Vol. 74, No. 3, 2011, pp. 163-165.

[3] P. Gogate and K. Kalua, "Blindness in Childhood in Developing Countries Time for a Reassessment?" PLOS Medicine, Vol. 6, No. 12, 2009, Article ID: e1000177.

[4] M. E. Wilson and S. K. Pandey, "Paediatric Cataract Blindness in the Developing World Surgical Techniques and Intraocular Lenses in the New Millennium," British Journal of Ophthalmology, Vol. 87, No. 1, 2003, pp. 14-19.

[5] K. M. de Carvalho and N. Minguini, "Characteristics of a Pediatric Low-Vision Population," Journal of Pediatric Ophthalmology and Strabismus, Vol. 35, No. 3, 1998, pp. 162-165.

[6] W. C. Owens and W. F. Hughes, "Results of Surgical Treatment of Congenital Cataract," Archives of Ophthalmology, Vol. 39, No. 3, 1948, pp. 339-350. doi:10.1001/archopht.1948.00900020346009

[7] G. Msukwa and M. Njuguna, "Cataract in Children Attending Schools for the Blind and Resource Centers in Eastern Africa," Ophthalmology, Vol. 116, 2009, pp. 10091012. doi:10.1016/j.ophtha.2008.12.020

[8] R. Dandona and L. Dandona, "Review of Findings of the Andhra Pradesh Eye Disease Study: Policy Implications for Eye-Care Services," Indian Journal of Ophthalmology, Vol. 49, No. 4, 2001, pp. 215-234.

[9] A. R. Vasavada, S. A. Vasavada, N. Bobrova, M. R. Praveen, S. K. Shah, V. A. Vasavada, et al., "Outcomes of Pediatric Cataract Surgery in Anterior Persistent Fetal Vasculature," Journal of Cataract \& Refractive Surgery, Vol. 38, No. 5, 2012, pp. 849-857. doi:10.1016/j.jcrs.2011.11.045

[10] R. M. Robb and R. A. Petersen, "Outcome of Treatment for Bilateral Congenital Cataracts," Transactions of the American Ophthalmological Society, Vol. 90, 1992, pp. 
183-194

[11] J. Francois "Late Results of Congenital Cataract Surgery," Ophthalmology, Vol. 86, No. 9, 1979, pp. 1586-1598.

[12] D. A. Hiles and P. H. Wallar, "Visual Results Following Infantile Cataract Surgery," International Ophthalmology Clinics, Vol. 17, No. 4, 1977, pp. 265-282.

[13] H. G. Scheie, "Aspiration of Congenital or Soft Cataracts: A New Technique," American Journal of Ophthalmology, Vol. 50, 1960, pp. 1048-1056.

[14] D. Taylor, "Choice of Surgical Technique in the Management of Congenital Cataract," Transactions of OphthaImological Societies of United Kingdom, Vol. 101, No. 1, 1981, pp. 114-117.

[15] M. M. Parks, "Posterior Lens Capsulectomy during Primary Cataract Surgery in Children," Ophthalmology, Vol. 90, No. 4, 1983, pp. 344-345.

[16] G. L. Rogers, C. L. Tishler and B. H. Tsou, "Visual Acuities in Infants with Congenital Cataracts Operated on Prior to 6 Months of Age," Archives of Ophthalmology, Vol. 99, No. 6, 1981, pp. 999-1003. doi:10.1001/archopht.1981.03930010999002

[17] S. S. Gelbart, C. S. Hoyt, G. Jastrebski and E. Marg, "Long-Term Visual Results in Bilateral Congenital Cataracts," American Journal of Ophthalmology, Vol. 93, No. 5, 1982, pp. 615-621.

[18] D. Taylor, Vaegan and J. A. Morris, "Amblyopia in Bilateral Infantile and Juvenile Cataract, Relationship to Timing of Treatment," Transactions of Ophthalmological Societies of United Kingdom, Vol. 99, No. 1, 1979, pp. 170-175.

[19] M. Yamamoto and M. Dogru, "Visual Function Fol- lowing Congenital Cataract Surgery," Japanese Journal of Ophthalmology, Vol. 42, No. 5, 1998, pp. 411-416. doi:10.1016/S0021-5155(98)00039-2

[20] R. H. Trivedi and M. E. Wilson, "Accuracy of the Holla- day 2 Intraocular Lens Formula for Pediatric Eyes in the Absence of Preoperative Refraction," Journal of Cataract \& Refractive Surgery, Vol. 37, No. 7, 2011, pp. 12391243. doi:10.1016/i.jcrs.2011.01.021

[21] S. K. McClatchey, "Choosing IOL Power in Pediatric Cataract Surgery," International Ophthalmology Clinics, Vol. 50, No. 4, 2010, pp. 115-123. doi:10.1097/IIO.0b013e3181f0f $2 \mathrm{e} 0$

[22] N. G. Congdon and S. Ruiz, "Determinants of Pediatric Cataract Program Outcomes and Follow-Up in a Large Series in Mexico," Journal of Cataract \& Refractive Surgery, Vol. 33, No. 10, 2007, pp. 1775-1780. doi:10.1016/j.jers.2007.06.025

[23] M. L. Yang and C. H. Hou, "Clinical Characteristics and Surgical Outcomes of Pediatric Cataract in Taiwan," Graefe's Archive for Clinical and Experimental Ophthalmology, Vol. 244, No. 11, 2006, pp. 1485-1490. doi:10.1007/s00417-006-0308-4

[24] R. Khandekar and A. Sudhan, "Pediatric Cataract and Surgery Outcomes in Central India a Hospital Based Study," Indian Journal of Medical Sciences, Vol. 61, No. 1, 2007, pp. 15-20. doi:10.4103/0019-5359.29593

[25] A. Magli and A. Iovine, "Strabismus in Developmental Cataract," European Journal of Ophthalmology, Vol. 18, No. 4, 2006, pp. 540-543.

[26] N. Spanou and L. Alexopoulos, "Strabismus in Pediatric Lens Disorders," Journal of Pediatric Ophthalmology and Strabismus, Vol. 48, No. 3, 2011, pp. 163-166. doi:10.3928/01913913-20100618-05

[27] P. Hochstrasser and B. Gloor, "Surgical Results of Uniand Bilateral Congenital and Traumatic Cataract in Infancy to Adolescence," Klin Monatsbl Augenheilkd, Vol. 204, No. 5, 1994, pp. 274-278. doi:10.1055/s-2008-1035534 